\title{
Acetylation of $\mathbf{N}$-terminus and two internal amino acids is dispensable for degradation of a protein that aberrantly engages the endoplasmic reticulum translocon
}

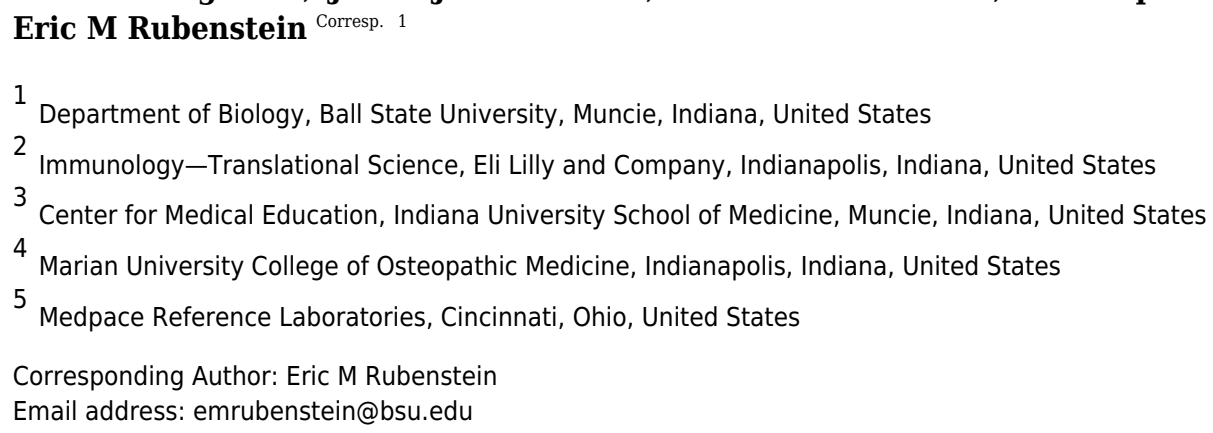

Conserved homologues of the Hrdl ubiquitin ligase target for degradation proteins that persistently or aberrantly engage the endoplasmic reticulum translocon, including mammalian apolipoprotein B (apoB; the major protein component of low-density lipoproteins) and the artificial yeast protein Deg1-Sec62. A complete understanding of the molecular mechanism by which translocon-associated proteins are recognized and degraded may inform the development of therapeutic strategies for cholesterol-related pathologies. Both apoB and Deg1-Sec62 are extensively post-translationally modified. Mass spectrometry of a variant of Deg1-Sec62 revealed that the protein is acetylated at the N-terminal methionine and two internal lysine residues. $\mathrm{N}$-terminal and internal acetylation regulates the degradation of a variety of unstable proteins. However, preventing $\mathrm{N}$-terminal and internal acetylation had no detectable consequence for Hrd1mediated proteolysis of Deg1-Sec62. Our data highlight the importance of empirically validating the role of post-translational modifications and sequence motifs on protein degradation, even when such elements have previously been demonstrated sufficient to destine other proteins for destruction. 
1 Acetylation of $\mathbf{N}$-terminus and two internal amino acids is dispensable for degradation of a

2 protein that aberrantly engages the endoplasmic reticulum translocon

3

4 Sarah M. Engle ${ }^{1,2,6}$, Justin J. Crowder ${ }^{1,3,6}$, Sheldon G. Watts ${ }^{1,4}$, Christopher J. Indovina ${ }^{1}$, Samuel 5 Z. Coffey ${ }^{1,5}$, Eric M. Rubenstein ${ }^{1}$

6

$7 \quad{ }^{1}$ Department of Biology, Ball State University, Muncie, Indiana, USA

$8{ }^{2}$ Current Address: Immunology_Translational Science, Eli Lilly and Company, Indianapolis, 9 Indiana, USA

103 Current Address: Center for Medical Education, Indiana University School of Medicine, 11 Muncie, Indiana, USA

$12{ }^{4}$ Current Address: Marian University College of Osteopathic Medicine, Indianapolis, Indiana, 13 USA.

$14{ }^{5}$ Current Address: Medpace Reference Laboratories, Cincinnati, Ohio, USA

$15{ }^{6}$ Sarah M. Engle and Justin J. Crowder are co-first authors on this manuscript.

17 Corresponding Author:

18 Eric M. Rubenstein

19

20 Email address: emrubenstein@bsu.edu

21

22 


\section{ABSTRACT}

25 Conserved homologues of the Hrd1 ubiquitin ligase target for degradation proteins that 26 persistently or aberrantly engage the endoplasmic reticulum translocon, including mammalian 27 apolipoprotein B (apoB; the major protein component of low-density lipoproteins) and the 28 artificial yeast protein Degl-Sec62. A complete understanding of the molecular mechanism by 29 which translocon-associated proteins are recognized and degraded may inform the development 30 of therapeutic strategies for cholesterol-related pathologies. Both apoB and Deg1-Sec62 are 31 extensively post-translationally modified. Mass spectrometry of a variant of Deg1-Sec62 32 revealed that the protein is acetylated at the $\mathrm{N}$-terminal methionine and two internal lysine 33 residues. N-terminal and internal acetylation regulates the degradation of a variety of unstable 34 proteins. However, preventing N-terminal and internal acetylation had no detectable 35 consequence for Hrd1-mediated proteolysis of Deg1-Sec62. Our data highlight the importance of empirically validating the role of post-translational modifications and sequence motifs on protein

37 degradation, even when such elements have previously been demonstrated sufficient to destine 38 other proteins for destruction. 
40

41

42

43

44

45

46

47

48

49

50

51

52

53

54

55

56

57 58 al. 2009). The ER-resident E3 Doa10 (TEB4/MARCH-VI in mammals) ubiquitylates soluble and 59 transmembrane proteins with cytosolic degrons (ERAD-C substrates) and participates in the 60 degradation of some ERAD-M substrates (Habeck et al. 2015; Huyer et al. 2004; Metzger et al. 61 2008; Ravid et al. 2006). Non-ER-resident E3s also contribute to the proteolysis of ER-localized

\section{INTRODUCTION}

0

Regulated protein degradation is crucial for cellular homeostasis. Misfolded, mislocalized, or otherwise aberrant proteins are targeted for destruction by the ubiquitin-proteasome system (UPS) (Finley et al. 2012). In addition, many proteins (e.g. cyclins and transcription factors) undergo regulated UPS-dependent degradation to meet cellular or organismal needs (Hickey 2016; Nakayama \& Nakayama 2006; Rubenstein \& Hochstrasser 2010). Enzymes called ubiquitin ligases (E3s) covalently transfer multiple copies of the small polypeptide ubiquitin to substrate proteins, marking them for destruction by the proteasome (Kleiger \& Mayor 2014). E3s, or their associated protein co-factors, recognize degrons (degradation signals) within their substrates. Degrons vary widely and include amino acid sequences, post-translational modifications (PTMs), and other structural features (Ravid \& Hochstrasser 2008).

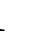

Aberrant or physiologically unstable proteins at the endoplasmic reticulum (ER) are targeted for proteasomal destruction by one of multiple ER-Associated Degradation (ERAD) mechanisms 4 (Ruggiano et al. 2014). In the budding yeast Saccharomyces cerevisiae, multiple E3s (each with

55 mammalian homologs) participate in ERAD (Zattas \& Hochstrasser 2015). The ER-resident E3

66 Hrd1 (HRD1 and gp78 in mammals) recognizes proteins with luminal or intramembrane degrons 7 (ERAD-L or ERAD-M substrates, respectively) (Carvalho et al. 2006; Gauss et al. 2006; Sato et 
62 proteins. For example, the cytosolic E3 Ubr1 redundantly targets some Doa10 and Hrd1

63 substrates for degradation (Stolz et al. 2013). Recently, we and others found that translationally

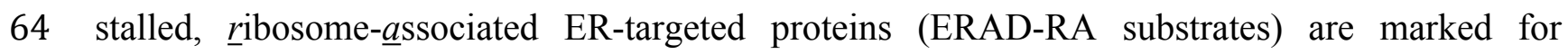

65 degradation by the cytosolic ribosome quality control E3 Rkr1/Ltn1 (Listerin in mammals)

66 (Arakawa et al. 2016; Crowder et al. 2015; von der Malsburg et al. 2015).

67

68 Other proteins are targeted for Hrd1-dependent degradation after they have persistently or 69 aberrantly engaged the ER translocon in a mechanism termed ERAD-T (Rubenstein et al. 2012).

70 For instance, the primary component of mammalian low-density lipoproteins (LDLs),

71 apolipoprotein $\mathrm{B}$ (apoB), arrests during translocation. Translocation proceeds upon interaction of

72 the luminally exposed N-terminal portion of apoB with its lipid binding partners, and an LDL

73 particle is assembled. When lipid binding is impaired, the Hrd1 homologue gp78 recognizes and

74 targets the translocon-associated, unassembled apoB for proteasomal degradation (Fisher et al.

75 2011; Liang et al. 2003; Pariyarath et al. 2001; Rutledge et al. 2009; Yeung et al. 1996).

76 Consistent with conservation of translocon-associated quality control mediated by ERAD

77 machinery, Hrd1 marks for destruction an apoB variant that persistently associates with the

78 translocon when expressed in yeast cells (Hrizo et al. 2007; Rubenstein et al. 2012).

79

80 Fusion of Degl (the first 67 amino acids of the transcriptional repressor MAT $\alpha 2$ ) to the N-

81 terminus of the otherwise stable, two-transmembrane yeast protein Sec62 triggers aberrant post-

82 translational translocation of the cytosolic N-terminal Sec62 tail (Rubenstein et al. 2012; Figure

83 1A). Translocon occupancy by the Degl-Sec62 fusion protein is likely to be prolonged, as a 84 disulfide linkage forms between cysteine residues in Degl-Sec62 and the translocon channel 
85 interior (Scott \& Schekman 2008). Following aberrant translocon engagement, Hrd1 targets

86 Deg1-Sec62 for proteasomal degradation. Mutation of either amino acid participating in this

87 disulfide linkage substantially abrogates Hrd1-dependent degradation, suggesting that this

88 persistent interaction is prerequisite to Hrd1-dependent degradation (Rubenstein et al. 2012).

89 Thus, Deg1-Sec62 may function as a model substrate for proteins that persistently or aberrantly

90 engage the ER translocon, such as apoB.

91

92 Degradation of many unstable proteins, including several Hrd1 substrates, depends on their PTM 93 status (Aebi et al. 2010; Clerc et al. 2009; Goder \& Melero 2011; Hirayama et al. 2008; Quan et 94 al. 2008; Spear \& Ng 2005; Vashist et al. 2001; Xu et al. 2013; Zattas et al. 2013). Following 95 translocon engagement, Degl-Sec62 becomes heavily modified in a manner that correlates with 96 its Hrd1-dependent degradation. Deg1-Sec62 is decorated by N-linked glycosylation and O97 linked mannosylation. However, preventing carbohydrate addition does not detectably affect 98 Hrd1-dependent degradation or completely abolish PTM of Degl-Sec62 (Rubenstein et al. 2012). These data suggest that the protein is modified in manners other than glycosylation that may be hypothesized to influence protein behavior and degradation.

101

102 In this study, we subjected Deg1-Sec62 to mass spectrometry (MS) analysis and found that it is 103 acetylated on three amino acids (Met1, Lys3, and Lys7). Since N-terminal and internal 104 acetylation regulates the degradation of other UPS substrates (Hwang et al. 2010; Lee et al. 105 2016; Nguyen et al. 2016; Zattas et al. 2013), and behavior of the translocon-associated ERAD 106 substrate apoB is influenced by acetylation (Brown et al. 1980; Brown et al. 1979; Weisgraber et 107 al. 1978), we hypothesized that Hrd1-dependent degradation of Degl-Sec62 is influenced by 
108 acetylation. However, simultaneously inhibiting all three acetylation events did not affect Hrd1109 mediated proteolysis of Deg1-Sec62. Thus, acetylation of Met1, Lys3, and Lys7 of the model 110 unstable, translocon-associated Degl-Sec62 protein is not required for targeting by the Hrd1 111 ubiquitin ligase. 


\section{MATERIALS \& METHODS}

113

114 Yeast and bacterial methods. Yeast strains and plasmids used in this study are presented in

115 Tables 1 and 2, respectively. Standard methods were used for manipulation of yeast strains

116 (Guthrie \& Fink 2004). Yeast cells were grown in synthetic defined medium (Guthrie \& Fink

117 2004). Galactose was included in growth medium instead of glucose to induce expression of

118 Deg1-Sec62-N153D (driven by the GAL1/10 promoter (Johnston \& Davis 1984)) for protein

119 purification. Plasmids were manipulated using PCR-based site-directed mutagenesis using

120 primers presented in Table 2. Mutagenesis was confirmed by digestion with restriction enzymes

121 and plasmid sequencing.

122

123 Yeast cell harvest and immunoprecipitation. Overnight cultures of yeast cells grown in

124 plasmid-selective medium containing glucose were diluted to an optical density at $600 \mathrm{~nm}$

$125\left(\mathrm{OD}_{600}\right)$ of 0.2 in plasmid-selective medium containing galactose. Cultures were incubated,

126 shaking, at $30^{\circ} \mathrm{C}$ until the $\mathrm{OD}_{600}$ reached 1.5 . Approximately $15,000 \mathrm{OD}_{600}$ units $(10 \mathrm{~L})$ of

127 logarithmically growing yeast cells were harvested by centrifugation in $1 \mathrm{~L}$ batches. Each batch

128 of yeast cells was pelleted by centrifugation for $5 \mathrm{~min}$ at 3,800 x $\mathrm{g}$, snap-frozen with liquid

129 nitrogen, and stored at $-80^{\circ} \mathrm{C}$ until lysis. Yeast cell pellets were thawed on ice and suspended in

130 an equal volume of Triton X lysis buffer (500 mM NaCl, $50 \mathrm{mM}$ HEPES pH 7.5, 5 mM EDTA,

131 1\% Triton X-100) supplemented with protease inhibitors (1 tablet cOmplete Mini Protease

132 Inhibitors (Roche Diagnostics, Indianapolis, IN) per $5 \mathrm{~mL}$ buffer, $10 \mu \mathrm{g} / \mathrm{mL}$ pepstatin A) and

133 phosphatase inhibitors ( $1 \mathrm{mM}$ sodium fluoride, $0.5 \mathrm{mM}$ sodium pyrophosphate). Volumes of

134 glass beads approximately equal to the volumes of yeast cell pellets were added, and cell 
135 suspensions were vortexed $12 \times 30 \mathrm{sec}$ at $4^{\circ} \mathrm{C}$, with two min on ice between rounds of vortexing.

136 Lysed cells were centrifuged at $8,700 \mathrm{x}$ g for $10 \mathrm{~min}$ at $4^{\circ} \mathrm{C}$. The supernatants were subsequently

137 centrifuged at $20,000 \mathrm{x} \mathrm{g}$ for $10 \mathrm{~min}$ at $4^{\circ} \mathrm{C}$. The supernatants were preserved. Protein

138 concentration was determined using the Bradford Assay.

139

140 Protein from cells expressing Deg1-Sec62-N153D (which possesses a FLAG affinity tag) was

141 subjected to anti-FLAG immunoprecipitation. Briefly, $250 \mathrm{mg}$ of protein extract was incubated,

142 rotating, for $2.5 \mathrm{hr}$ at $4^{\circ} \mathrm{C}$ in the presence of $600 \mu \mathrm{l}$ of $50 \%$ aFLAG M2-conjugated agarose

143 affinity gel (Sigma-Aldrich, St. Louis, MO) equilibrated with Triton X lysis buffer. The affinity

144 gel was washed ten times with ice-cold immunoprecipitation wash buffer $(500 \mathrm{mM} \mathrm{NaCl}, 50$

145 mM HEPES pH 7.5, 5 mM EDTA, 1\% Triton X-100, 0.1\% sodium dodecyl sulfate). The Degl-

146 Sec62-N153D protein was eluted from the affinity gel by incubation with $75 \mathrm{mM} 3 \times \mathrm{xLAG}$

147 peptide (GenScript, Piscataway, NJ) in a total volume of $2 \mathrm{~mL}$ of immunoprecipitation wash

148 buffer, rocking, at $4^{\circ} \mathrm{C}$ for $30 \mathrm{~min}$. The affinity gel was pelleted by centrifugation at $6,900 \times \mathrm{g}$,

149 and the supernatant with eluted protein was transferred to fresh tubes and preserved. To reduce

150 disulfide linkages and alkylate cysteine side chains prior to mass spectrometry, sequential

151 addition of and incubation with dithiothreitol ( $5 \mathrm{mM}$ final concentration, $\left.56^{\circ} \mathrm{C}, 30 \mathrm{~min}\right)$ and

152 iodoacetamide ( $7 \mathrm{mM}$ final concentration, room temperature, in a light-proof container) was

153 performed.

154

155 Purified, reduced, and alkylated Deg1-Sec62-N153D protein was concentrated by trichloroacetic 156 acid (TCA) precipitation. TCA was added to a final concentration of $20 \%$. The sample was

157 vortexed, incubated at $4^{\circ} \mathrm{C}$ for $20 \mathrm{~min}$, and centrifuged at $20,000 \mathrm{x} \mathrm{g}$ at $4^{\circ} \mathrm{C}$ for $20 \mathrm{~min}$. The 
158 pellet was washed once with $4{ }^{\circ} \mathrm{C} 10 \%$ TCA and once with ice-cold $100 \%$ high-performance

159 liquid chromatography-grade acetone. The pellet was air-dried at room temperature for $10 \mathrm{~min}$

160 and fully dried in a vacuum concentrator for $30 \mathrm{~min}$. The pellet was resuspended in $2 \mathrm{X}$ Laemmli

161 Sample Buffer, heated at $95^{\circ} \mathrm{C}$ for $5 \mathrm{~min}$, and separated by sodium dodecyl sulfate-

162 polyacrylamide gel electrophoresis (SDS-PAGE). The SDS-PAGE gel was stained in GelCode

163 Blue (Thermo Scientific, Waltham, MA), and bands corresponding to Degl-Sec62-N153D were

164 excised with a fresh razor blade.

165

166 Mass spectrometry. Similar methods for mass spectrometry data acquisition and analysis have

167 been described (Hughes Hallett et al. 2015). The gel slice containing Degl-Sec62-N153D was

168 washed 15 min each with water, 50\% (v/v) acetonitrile, 100\% (v/v) acetonitrile, $100 \mathrm{mM}$

169 ammonium bicarbonate, and $100 \mathrm{mM}$ ammonium bicarbonate in $50 \%(\mathrm{v} / \mathrm{v})$ acetonitrile. The

170 solution was removed, and the gel slice was dried by vacuum centrifugation. Protein in the dried

171 gel slice was reduced by immersion in $10 \mathrm{mM}$ dithiothreitol/100 $\mathrm{mM}$ ammonium bicarbonate at

$17256^{\circ} \mathrm{C}$ for $45 \mathrm{~min}$. The solution was removed and discarded. Protein in the gel slice was alkylated

173 by immersion in $55 \mathrm{mM}$ iodoacetamide $/ 100 \mathrm{mM}$ ammonium bicarbonate in the dark at ambient

174 temperature for $30 \mathrm{~min}$. The solution was removed and discarded. The gel slice was washed with

$175100 \mathrm{mM}$ ammonium bicarbonate for $10 \mathrm{~min}$ on a shaker. An equal amount of acetonitrile was

176 added, and the slice was incubated, shaking, for $10 \mathrm{~min}$. The solution was discarded and the gel

177 slice was dried by vacuum centrifugation for $45 \mathrm{~min}$. The gel slice was cooled on ice. The slice

178 was immersed in an ice-cold solution of $12.5 \mathrm{ng} / \mu \mathrm{L}$ trypsin (Promega, Madison, WI) in $100 \mathrm{mM}$

179 ammonium bicarbonate. After 45 min, the trypsin solution was discarded, and the gel slice was

180 immersed in $50 \mathrm{mM}$ ammonium bicarbonate for $16 \mathrm{hr}$ at $37^{\circ} \mathrm{C}$ on a shaker. The sample was 
181 sedimented by microcentrifugation, and the supernatant was collected and retained. Peptides

182 were extracted from the gel slice by immersing the slice in $0.1 \%(\mathrm{v} / \mathrm{v})$ trifluoroacetic acid (TFA)

183 and mixing at ambient temperature for $30 \mathrm{~min}$. An equal volume of acetonitrile was added, and

184 the sample was mixed for an additional $30 \mathrm{~min}$. The sample was sedimented by

185 microcentrifugation, and the supernatant from this extraction was pooled with the post-digestion

186 supernatant. This pool was divided into 4 tubes and concentrated by vacuum centrifugation. One

187 tube was further digested with chymotrypsin (Roche Diagnostics) by resuspending the tryptically

188 digested peptides in a solution of $100 \mathrm{mM}$ Tris- $\mathrm{HCl} / 10 \mathrm{mM}$ calcium chloride $(\mathrm{pH}$ 8) containing

$1890.25 \mu \mathrm{g}$ of chymotrypsin. Digestion was performed at room temperature with mixing overnight.

190 The chymotrypsin was quenched by adding TFA to a final concentration of $0.5 \%(\mathrm{v} / \mathrm{v})$. One of

191 the trypsin digests and the trypsin/chymotrypsin digest were desalted using ZipTip $\mathrm{C}_{18}$

192 (Millipore, Billerica, MA) and eluted with 70\% (v/v) acetonitrile in $0.1 \%(\mathrm{v} / \mathrm{v})$ TFA. The

193 desalted material was concentrated to dryness in a centrifugal evaporator.

194

195 The proteolytically digested samples were suspended in $20 \mu \mathrm{L}$ of $2 \%$ acetonitrile (v/v) in $0.1 \%$

$196(\mathrm{v} / \mathrm{v})$ formic acid, and $18 \mu \mathrm{L}$ was analyzed by liquid chromatography/electrospray ionization

197 tandem MS (LC/ESI MS/MS) with a Thermo Scientific Easy-nLC II (Thermo Scientific)

198 coupled to an Orbitrap Elite ETD (Thermo Scientific) mass spectrometer using a trap-column

199 configuration as described (Licklider et al. 2002). Inline desalting was accomplished using a

200 reversed-phase trap column $(100 \mu \mathrm{m} \times 20 \mathrm{~mm})$ packed with Magic $\mathrm{C}_{18} \mathrm{AQ}(5 \mu \mathrm{m}, 200 \AA$ resin;

201 Michrom Bioresources, Auburn, CA) followed by peptide separations on a reversed-phase

202 column $(75 \mu \mathrm{m} \times 250 \mathrm{~mm})$ packed with Magic $\mathrm{C}_{18} \mathrm{AQ}(5 \mu \mathrm{m}, 100 \AA$ resin $)$ directly mounted on

203 the electrospray ion source. A 45 -min gradient from $2 \%$ to $35 \%(\mathrm{v} / \mathrm{v})$ acetonitrile in $0.1 \%(\mathrm{v} / \mathrm{v})$ 
204 formic acid at a flow rate of $400 \mathrm{~nL} / \mathrm{min}$ was used for chromatographic separations. A spray

205 voltage of $2500 \mathrm{~V}$ was applied to the electrospray tip, and the Orbitrap Elite instrument was 206 operated in the data-dependent mode, switching automatically between MS survey scans in the 207 Orbitrap (automatic gain control (AGC) target value 1,000,000, resolution 120,000, and injection 208 time $250 \mathrm{msec}$ ) with collision induced dissociation (CID) MS/MS spectra acquisition in the 209 linear ion trap (AGC target value of 10,000 and injection time $100 \mathrm{msec}$ ), higher-energy collision 210 induced dissociation (HCD) MS/MS spectra acquisition in the Orbitrap (AGC target value of $21150,000,15,000$ resolution, and injection time $250 \mathrm{msec}$ ), and electron transfer dissociation (ETD)

212 MS/MS spectra acquisition in the Orbitrap (AGC target value of 50,000, 15,000 resolution, and 213 injection time $250 \mathrm{msec}$ ). The three most intense precursor ions from the Fourier transform full 214 scan were each consecutively selected for fragmentation in the linear ion trap by CID with a 215 normalized collision energy of $35 \%$, fragmentation in the HCD cell with normalized collision 216 energy of $35 \%$, and fragmentation by ETD with $100 \mathrm{msec}$ activation time. Selected ions were 217 dynamically excluded for $30 \mathrm{sec}$.

219 Data analysis was performed using Proteome Discoverer 1.4 (Thermo Scientific). The data were 220 searched against the Saccharomyces Genome Database (downloaded 02/03/2011;

221 www.yeastgenome.org) that was appended with protein sequences of common contaminants and 222 the sequence for the Degl-Sec62-N153D protein. Searches were conducted as no-enzyme 223 search. The precursor ion tolerance was set to $10 \mathrm{ppm}$, and the fragment ion tolerance was set to 224 0.6 Da. Variable modifications included oxidation on methionine $(+15.995$ Da), 225 carbamidomethyl $(+57.021 \mathrm{Da})$ on cysteine, and acetylation on lysine and any N-terminus 
226 (+42.011 Da). All search results were run through the Percolator algorithm for false discovery

227 rate evaluation of the identified peptides.

228

229 Cycloheximide chase, cell lysis, and endoglycosidase $\mathbf{H}$ treatment. Cycloheximide chase 230 analysis was performed as described (Buchanan et al. 2016). Briefly, mid-logarithmic growth231 phase yeast cells were concentrated to $2.5 \mathrm{OD}_{600}$ units $/ \mathrm{ml}$ in fresh plasmid-selective media, and 232 cycloheximide was added to a final concentration of $250 \mu \mathrm{g} / \mathrm{ml} .950 \mu \mathrm{l}$ aliquots $\left(\sim 2.4 \mathrm{OD}_{600}\right.$ 233 units) of cells were harvested at the indicated time points following cycloheximide 234 administration and added to $50 \mu \mathrm{l}$ of ice-cold $20 \mathrm{X}$ stop mix (200 mM sodium azide, $5 \mathrm{mg} / \mathrm{ml}$ 235 bovine serum albumin) and placed on ice until the end of the chase. Proteins were liberated by 236 the post-alkaline protein extraction method (Kushnirov 2000; Watts et al. 2015). To assay 237 protein $\mathrm{N}$-linked glycosylation, protein extracts derived from $0.375 \mathrm{OD}_{600}$ units of cells were 238 supplemented with potassium acetate, $\mathrm{pH} 5.6$ (80 mM final concentration), and incubated at $23937^{\circ} \mathrm{C}$ for $2 \mathrm{hr}$ in the absence or presence of endoglycosidase $\mathrm{H}$ (Endo H; Roche Diagnostics).

241 Western blotting. Proteins were separated by SDS-PAGE and transferred to Immobilon 242 polyvinylidene fluoride membranes (Millipore). Membranes were blocked with 5\% skim milk in 243 Tris-buffered saline (TBS; $50 \mathrm{mM}$ Tris, $\mathrm{pH}$ 7.6, $136 \mathrm{mM} \mathrm{NaCl}$ ) for $60 \mathrm{~min}$ at room temperature 244 or overnight at $4^{\circ} \mathrm{C}$. All antibody incubations were performed for $60 \mathrm{~min}$ at room temperature in $2451 \%$ skim milk in TBS with $0.1 \%$ Tween 20 (TBS/T). To detect CPY*-HA, membranes were 246 incubated in the presence of monoclonal mouse anti-HA antibodies (Clone 16B12; Covance, 247 Princeton, NJ) at 1:1,000. To detect Pgk1, membranes were incubated in the presence of 248 monoclonal mouse anti-yeast Pgk1 antibodies (Clone 22C5D8; Life Technologies, Carlsbad, 
249 CA) at 1:20,000. Anti-HA and Anti-Pgk1 primary antibody incubations were followed by 250 incubation in the presence of Alexa-Fluor 680-conjugated Rabbit anti-Mouse $\operatorname{IgG}(\mathrm{H}+\mathrm{L})$ 251 secondary antibodies (Life Technologies, Carlsbad, CA) at 1:40,000. The Deg1-Sec62 protein 252 and its derivatives possess two tandem C-terminal Staphylococcus aureus Protein A tags (Hjelm 253 et al. 1975) and were detected directly with Alexa-Fluor 680-conjugated Rabbit anti-Mouse IgG $254(\mathrm{H}+\mathrm{L})$ secondary antibodies at 1:40,000. Membranes were imaged using an Odyssey CLx 255 Imaging System (LI-COR, Lincoln, NE). 


\section{RESULTS}

257

258 A model unstable translocon-associated protein is acetylated. We performed MS to gain

259 further insight into the nature of Degl-Sec62 PTM. We and others have previously mapped the

260 major N-linked glycosylation site to Asn153 (Rubenstein et al. 2012; Scott \& Schekman 2008).

261 In our previous work, mutation of Asn153 to a non-glycosylatable aspartic acid residue did not

262 detectably alter translocon engagement, additional PTM, or Hrd1-dependent degradation

263 (Rubenstein et al. 2012). Therefore, to simplify PTM analysis, we immunoprecipitated a variant

264 of Deg1-Sec62 (Deg1-Sec62-N153D) that harbors an asparagine-to-aspartic acid mutation at this

265 position from lysates of cells lacking the Hrd1 ubiquitin ligase. Purified Degl-Sec62-N153D was

266 separated by SDS-PAGE, and bands corresponding to Degl-Sec62-N153D were excised (Figure

267 1B) and proteolytically digested. Proteolytic processing of Deg1-Sec62-N153D with trypsin was

268 complemented by further digesting one half of the trypsin-digested material with chymotrypsin

269 to reduce large tryptic peptides into smaller sizes conducive to MS analysis. The trypsin and

270 trypsin-chymotrypsin digestions were subjected to MS-based acetylpeptide mapping, resulting in

271 a combined map that covered $73 \%$ of the protein sequence (Figure 1C). Acetylation was

272 identified with high confidence (with a false discovery rate of acetylated peptides of less than

$2731 \%$ ) on the N-terminus of the protein, Lys3, and Lys7. Manual visualization of the results

274 verified the high-confidence assignment of acetylation on the N-terminus and Lys3, while

275 manual visualization indicated acetylation of Lys7 should be considered a lower-confidence

276 result, in contradiction to the database search algorithm result. It is possible that additional lysine

277 residues are acetylated but were not detected due to incomplete coverage of the Deg1-Sec62- 
278 N153D protein. Representative tandem mass spectra identifying sites of acetylation are shown in

279 Figure 1D-F.

280

281 Acetylation of $\mathbf{N}$-terminus and two internal residues does not influence Hrd1-dependent

282

degradation of a model unstable translocon-associated protein. To determine if Hrd1-

283

dependent degradation of Degl-Sec62 is influenced by acetylation, we analyzed protein turnover

284

in the context of mutations predicted to prevent acetylation. Certain conditions trigger a switch in

285

E3 dependence for Deg1-Sec62 degradation from Hrd1 to Doa10. To evaluate Hrd1-dependent

286

287

288

289

290 291 (Rubenstein et al. 2012).

292

293

294

295

296

297

298

299

300

(

degradation exclusively, we used a version of Degl-Sec62 specifically resistant to Doa10-

dependent degradation. This variant, termed $\operatorname{Deg} 1^{*}$-Sec62, harbors two point mutations (F18S and I22T) and behaves like Deg1-Sec62 with respect to Hrd1-dependent degradation (Johnson et al. 1998; Rubenstein et al. 2012). Degl-Sec62 and Degl*-Sec62 have been used interchangeably to evaluate degradation requirements for proteins that aberrantly engage the ER translocon

The N-terminal methionine of Deg ${ }^{*}$-Sec62 is predicted to be acetylated by the NatB N-terminal acetyltransferase, which modifies proteins with the N-terminal Met-Asn dipeptide. Deleting the gene encoding the catalytic subunit of NatB (NAT3) is therefore predicted to abolish $\mathrm{N}$-terminal acetylation of $\operatorname{Deg} 1{ }^{*}-$ Sec62 (Hollebeke et al. 2012; Polevoda et al. 2009). To test the hypothesis that N-terminal acetylation regulates substrate degradation, we analyzed $\operatorname{Deg} l^{*}$-Sec62 turnover by cycloheximide chase in wild-type yeast, yeast lacking $H R D 1$, and yeast lacking NAT3 (Figure 2A). Consistent with previous reports, deletion of HRDl substantially increased steady state levels of Degl*-Sec62 and delayed protein degradation (Buchanan et al. 2016; Rubenstein et al. 
301 2012; Watts et al. 2015). By contrast, eliminating Nat3 from cells did not markedly impair

302 Degl*-Sec62 degradation. The control ERAD-L substrate CPY*-HA was stabilized in both

$303 h r d 1 \Delta$ and nat3s cells (Figure 2B), also consistent with previous reports (Hiller et al. 1996;

304 Zattas et al. 2013).

305

306 We note marginally impaired degradation (without an increase in steady state abundance) of $307 D e g{ }^{*}$-Sec62 in nat $3 \Delta$ cells compared to wild-type yeast (Figure $2 \mathrm{~A}$ ). This minor effect is likely 308 indirect, as NAT3 deletion destabilizes the Hrd1 co-factor Der1, loss of which subtly stabilizes 309 Deg1*-Sec62 (Rubenstein et al. 2012; Zattas et al. 2013). Degradation of a Degl*-Sec62 variant 310 with a mutation that abolishes the NatB consensus sequence (Deg ${ }^{*}$-Sec62-3R in Figure $2 \mathrm{C}$, 311 described below) supports the notion that N-terminal acetylation does not promote substrate 312 degradation.

314 To determine if internal acetylation influences $\operatorname{Deg}{ }^{*}$-Sec62 degradation, we mutated both 315 potentially acetylated lysine residues (at positions 3 and 7) to non-acetylatable arginine residues.

316 The resultant protein is referred to as $\operatorname{Deg}{ }^{*}{ }_{-}$Sec62-2R (the version of the protein with both 317 lysine residues intact is called Degl*-Sec62-0R in Figures 2C and 2D). Degl*-Sec62-2R 318 exhibited degradation kinetics similar to that of Degl*-Sec62 in wild-type cells (Figure 2C), and 319 its rapid degradation was Hrd1-dependent (Figure 2E). N-glycosylation of Degl*-Sec62 and its 320 derivatives only occurs following aberrant translocon engagement (Rubenstein et al. 2012).

321 Sensitivity to Endo H, which removes all N-linked glycans from yeast proteins, confirmed that

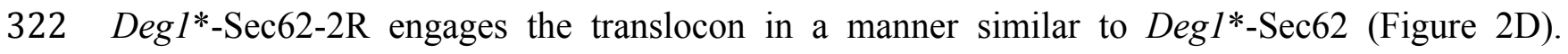


323 Therefore, acetylation of two lysine residues is dispensable for Hrd1-dependent degradation of a

324 protein that aberrantly and persistently engages the translocon.

325

326 It was formally possible that acetylation at any one of three positions (Met1, Lys3, or Lys7)

327 influences Hrd1-dependent degradation of Degl*-Sec62. We simultaneously abolished all three

328 acetylation events in two different ways. First, we generated a variant of $\operatorname{Deg} 1^{*}$-Sec62 with point

329 mutations predicted to prevent all three acetylation events. As for Degl*-Sec62-2R, lysine

330 residues at positions 3 and 7 were mutated to arginine. In addition, the second amino acid

331 (asparagine) was mutated to arginine. Proteins with an N-terminal Met-Arg dipeptide are not

332 predicted to be acetylated by any of the characterized N-terminal acetyltransferases (Polevoda et

333 al. 2009). The protein with three amino acids mutated to arginine is referred to as Degl*-Sec62-

334 3R. Degl*-Sec62-3R is degraded at a rate similar to that of fully acetylatable $\operatorname{Deg} 1{ }^{*}$-Sec62

335 (Figure 2C) in a Hrd1-dependent manner (Figure 2F). Endo H sensitivity confirmed that Degl*-

336 Sec62-3R engages the translocon in a manner similar to Degl*-Sec62 and Deg1*-Sec62-2R

337 (Figure 2D). Consistently, degradation of $\operatorname{Deg} 1{ }^{*}-$ Sec62-2R occurred at a similar rate in the 338 presence and absence of Nat3 (Figure 2E). 


\section{DISCUSSION}

341

342 Given that PTM of Deg1(*)-Sec62 correlates with its degradation by the Hrd1 pathway, and that

343 acetylation has been shown to influence the degradation of a number of unstable proteins,

344 including ERAD substrates, the hypothesis that acetylation regulates the degradation of a model

345 translocon-associated protein was attractive. However, our data strongly suggest that acetylation

346 of Met1, Lys3, and Lys7 within the model translocon-associated protein Degl*-Sec62 is not

347 required for aberrant translocon engagement or targeting by the Hrd1 ubiquitin ligase.

349 To purify a quantity of Deg1-Sec62-N153D protein sufficient for MS analysis, we took measures 350 to enhance its synthesis and impair its destruction. To increase synthesis, we placed the gene 351 encoding Deg1-Sec62-N153D under the control of the galactose-inducible GAL1 promoter 352 (Johnston \& Davis 1984). To reduce degradation, we expressed the construct in cells lacking 353 HRD1 (Rubenstein et al. 2012). We note that it is conceivable that such alterations alter the 354 manner in which the protein engages the translocon or undergoes PTM. High-level expression of 355 a normally unstable protein might saturate modifying enzymes or be subject to promiscuous 356 modification by PTM machinery.

357

358 N-terminal acetylation has been reported to regulate the degradation of multiple ERAD 359 substrates. Deleting the gene encoding the N-terminal acetyltransferase Nat3 has opposing, but 360 related, effects on Hrd1 substrates (Zattas et al. 2013). When its Nat3-mediated N-terminal 361 acetylation is prevented, the Hrd1 cofactor Der1 is converted into a Hrd1 substrate. Der1 362 functions in Hrd1-mediated ERAD-L; thus, proteolysis of Der1 in nat3s cells stabilizes the 
363 ERAD-L substrate CPY*. N-terminal acetylation has also been suggested to affect the

364 degradation of Doa10 substrates (Hwang et al. 2010; Ravid et al. 2006). The MAT $\alpha 2$

365 transcriptional repressor, from which the Degl degron is derived, is N-terminally acetylated in a

366 Nat3-dependent manner (Hwang et al. 2010). Reports suggest that Doa10 targets MAT $\alpha 2$ and

367 other ERAD-C substrates for degradation in a manner that requires $\mathrm{N}$-terminal acetylation as a

368 part of the N-end rule system. However, the extent to which acetylation affects Doa10 substrate

369 degradation varies among reports (Hwang et al. 2010; Ravid et al. 2006; Zattas et al. 2013).

370

371 Internal acetylation has also emerged as a positive and negative regulator of protein degradation

372 (Gronroos et al. 2002; Nguyen et al. 2016). Acetyltransferases modifying internal lysine residues

373 exist in the nucleus, cytosol, and ER (Pehar \& Puglielli 2013). In cases where internal

374 modification enhances degradation, acetylation may stabilize the interaction between substrate

375 and ubiquitin ligase (Jiang et al. 2011; Nguyen et al. 2016). In cases where internal modification

376 reduces degradation, acetylation may compete with ubiquitylation for lysine modification or

377 prevent substrate binding to ubiquitin ligases (Caron et al. 2005; Chang et al. 2016).

378 Interestingly, gp78-dependent binding to and ubiquitylation of the ER chaperone GRP78 is

379 enhanced by substrate deacetylation (Chang et al. 2016). Given the abundance of acetylated

380 proteins at the ER (Pehar et al. 2012), it would not be surprising if acetylation regulates ERAD

381 of a subset of unstable proteins. Further, acetylation of apoB, a physiological protein that

382 exhibits prolonged translocon association, influences uptake by target cells (Brown et al. 1980;

383 Brown et al. 1979; Weisgraber et al. 1978). To our knowledge, the role of acetylation in apoB

384 degradation has not been explored. 
386 The molecular mechanism by which Hrd1 recognizes the model translocon-associated protein 387 Degl-Sec62 remains obscure. Several protein co-factors that function with Hrd1 in the 388 destruction of other classes of ERAD substrates are dispensable for Degl-Sec62 degradation 389 (Rubenstein et al. 2012). Additionally, while post-translational modification of this protein 390 correlates with its Hrd1-dependent destruction, no modifications (save ubiquitylation) have been

391 shown to influence its degradation (Rubenstein et al. 2012; Scott \& Schekman 2008). Ongoing 392 investigations are being conducted to identify the factors involved in recognition and degradation 393 of proteins that persistently and aberrantly engage the ER translocon. Such factors may represent 394 therapeutic targets for cholesterol-related pathology.

395 


\section{CONCLUSIONS}

397

398 We have shown that a model unstable translocon-associated protein is N-terminally and 399 internally acetylated. Despite reported roles for acetylation in the regulation of degradation of 400 other unstable proteins, including multiple substrates of ER-resident ubiquitin ligases (Gronroos 401 et al. 2002; Hwang et al. 2010; Nguyen et al. 2016; Ravid et al. 2006; Zattas et al. 2013), 402 acetylation does not influence the degradation of the protein investigated in this study. Our 403 results demonstrate that context is crucially important in determining whether a particular PTM 404 will trigger degradation by the UPS. Indeed, while N-terminal acetylation status may seal the 405 degradative fate of several proteins (e.g. via the N-end rule pathway (Hwang et al. 2010)), our 406 data indicate that such rules are not absolute and emphasize that even the most reasonable 407 predictions must be empirically tested. 


\section{ACKNOWLEDGEMENTS}

410

411 We thank Mark Hochstrasser (Yale University; New Haven, CT) for sharing yeast strains and 412 plasmids. We thank Christopher Hickey (Yale University; New Haven, CT) and Robert Tomko 413 (Florida State University; Tallahassee, FL) for invaluable technical guidance. We thank Philip 414 Gafken (Fred Hutchinson Cancer Research Center; Seattle, WA) for providing outstanding 415 experimental assistance and support for this project. We thank Bryce Buchanan for assistance in 416 data analysis. We thank present and former members of the Rubenstein laboratory for providing 417 an enthusiastic and supportive environment.

418

419 


\section{REFERENCES}

422 Aebi M, Bernasconi R, Clerc S, and Molinari M. 2010. N-glycan structures: recognition and 423 processing in the ER. Trends Biochem Sci 35:74-82. 10.1016/j.tibs.2009.10.001

424 Arakawa S, Yunoki K, Izawa T, Tamura Y, Nishikawa S, and Endo T. 2016. Quality control of 425 nonstop membrane proteins at the ER membrane and in the cytosol. Sci Rep 6:30795.

426 10.1038/srep30795

427

Brown MS, Basu SK, Falck JR, Ho YK, and Goldstein JL. 1980. The scavenger cell pathway for 428 lipoprotein degradation: specificity of the binding site that mediates the uptake of negatively-charged LDL by macrophages. $J$ Supramol Struct 13:67-81.

431 432 433 434 435 436 437 438 439 440 441 442 $10.1002 /$ jss.400130107

Brown MS, Goldstein JL, Krieger M, Ho YK, and Anderson RG. 1979. Reversible accumulation of cholesteryl esters in macrophages incubated with acetylated lipoproteins. J Cell Biol 82:597-613.

Buchanan BW, Lloyd ME, Engle SM, and Rubenstein EM. 2016. Cycloheximide Chase Analysis of Protein Degradation in Saccharomyces cerevisiae. J Vis Exp. 10.3791/53975

Carvalho P, Goder V, and Rapoport TA. 2006. Distinct ubiquitin-ligase complexes define convergent pathways for the degradation of ER proteins. Cell 126:361-373.

Chen M, and Cook KD. 2007. Oxidation artifacts in the electrospray mass spectrometry of Abeta Peptide. Anal Chem 79:2031-2036. 10.1021/ac061743r

Chen P, Johnson P, Sommer T, Jentsch S, and Hochstrasser M. 1993. Multiple ubiquitinconjugating enzymes participate in the in vivo degradation of the yeast MAT alpha 2 repressor. Cell 74:357-369. 
443 Clerc S, Hirsch C, Oggier DM, Deprez P, Jakob C, Sommer T, and Aebi M. 2009. Htm1 protein 444 generates the N-glycan signal for glycoprotein degradation in the endoplasmic reticulum. 445 J Cell Biol 184:159-172. 10.1083/jcb.200809198

446 Crowder JJ, Geigges M, Gibson RT, Fults ES, Buchanan BW, Sachs N, Schink A, Kreft SG, and 447 Rubenstein EM. 2015. Rkr1/Ltn1 Ubiquitin Ligase-Mediated Degradation of 448 449 Translationally Stalled Endoplasmic Reticulum Proteins. J Biol Chem 290:18454-18466. 10.1074/jbc.M115.663559

450

451

Finley D, Ulrich HD, Sommer T, and Kaiser P. 2012. The ubiquitin-proteasome system of Saccharomyces cerevisiae. Genetics 192:319-360. 10.1534/genetics.112.140467

452 Fisher EA, Khanna NA, and McLeod RS. 2011. Ubiquitination regulates the assembly of VLDL 453 454 in HepG2 cells and is the committing step of the apoB-100 ERAD pathway. J Lipid Res

455

456

457

458

459

460

461

462 463

52:1170-1180. 10.1194/jlr.M011726

Gauss R, Sommer T, and Jarosch E. 2006. The Hrd1p ligase complex forms a linchpin between ER-lumenal substrate selection and Cdc48p recruitment. Embo $J$ 25:1827-1835. 10.1038/sj.emboj.7601088

Goder V, and Melero A. 2011. Protein O-mannosyltransferases participate in ER protein quality control. J Cell Sci 124:144-153. 10.1242/jcs.072181

Gronroos E, Hellman U, Heldin CH, and Ericsson J. 2002. Control of Smad7 stability by competition between acetylation and ubiquitination. Mol Cell 10:483-493.

Guthrie C, and Fink GR. 2004. Guide to Yeast Genetics and Molecular and Cell Biology. San Diego: Elsevier. 
464 Habeck G, Ebner FA, Shimada-Kreft H, and Kreft SG. 2015. The yeast ERAD-C ubiquitin ligase 465 466

467 Hickey CM. 2016. Degradation elements coincide with cofactor binding sites in a short-lived 468 transcription factor. Cell Logist 6:e1157664. 10.1080/21592799.2016.1157664

469

470

471 472

473

474

475

476

477

478

479

480

481

482

483

484

Doa10 recognizes an intramembrane degron. $J$ Cell Biol 209:261-273. $10.1083 /$ jcb. 201408088

Hiller MM, Finger A, Schweiger M, and Wolf DH. 1996. ER degradation of a misfolded luminal protein by the cytosolic ubiquitin-proteasome pathway. Science 273:1725-1728.

Hirayama H, Fujita M, Yoko-o T, and Jigami Y. 2008. O-mannosylation is required for degradation of the endoplasmic reticulum-associated degradation substrate Gas $1 * \mathrm{p}$ via the ubiquitin/proteasome pathway in Saccharomyces cerevisiae. J Biochem 143:555-567. $10.1093 / \mathrm{jb} / \mathrm{mvm} 249$

Hjelm H, Sjodahl J, and Sjoquist J. 1975. Immunologically active and structurally similar fragments of protein A from Staphylococcus aureus. Eur J Biochem 57:395-403.

Hollebeke J, Van Damme P, and Gevaert K. 2012. N-terminal acetylation and other functions of Nalpha-acetyltransferases. Biol Chem 393:291-298. 10.1515/hsz-2011-0228

Hrizo SL, Gusarova V, Habiel DM, Goeckeler JL, Fisher EA, and Brodsky JL. 2007. The Hsp110 molecular chaperone stabilizes apolipoprotein B from endoplasmic reticulumassociated degradation (ERAD). J Biol Chem 282:32665-32675. kush10.1074/jbc.M705216200

Aebi M, Bernasconi R, Clerc S, and Molinari M. 2010. N-glycan structures: recognition and processing in the ER. Trends Biochem Sci 35:74-82. 10.1016/j.tibs.2009.10.001 
485 Arakawa S, Yunoki K, Izawa T, Tamura Y, Nishikawa S, and Endo T. 2016. Quality control of 486

487 nonstop membrane proteins at the ER membrane and in the cytosol. Sci Rep

488

489

490

491

492

493

494

495

496

497

498

499

500

501

502

503

504

505

506 6:30795. 10.1038/srep30795

Brown MS, Basu SK, Falck JR, Ho YK, and Goldstein JL. 1980. The scavenger cell pathway for lipoprotein degradation: specificity of the binding site that mediates the uptake of negatively-charged LDL by macrophages. J Supramol Struct 13:67-81. $10.1002 /$ jss.400130107

Brown MS, Goldstein JL, Krieger M, Ho YK, and Anderson RG. 1979. Reversible accumulation of cholesteryl esters in macrophages incubated with acetylated lipoproteins. J Cell Biol 82:597-613.

Buchanan BW, Lloyd ME, Engle SM, and Rubenstein EM. 2016. Cycloheximide Chase Analysis of Protein Degradation in Saccharomyces cerevisiae. J Vis Exp. $10.3791 / 53975$

Caron C, Boyault C, and Khochbin S. 2005. Regulatory cross-talk between lysine acetylation and ubiquitination: role in the control of protein stability. Bioessays 27:408-415. 10.1002/bies. 20210

Carvalho P, Goder V, and Rapoport TA. 2006. Distinct ubiquitin-ligase complexes define convergent pathways for the degradation of ER proteins. Cell 126:361-373.

Chang YW, Tseng CF, Wang MY, Chang WC, Lee CC, Chen LT, Hung MC, and Su JL. 2016. Deacetylation of HSPA5 by HDAC6 leads to GP78-mediated HSPA5 ubiquitination at K447 and suppresses metastasis of breast cancer. Oncogene 35:1517-1528. 10.1038/onc. 2015.214 
507 Clerc S, Hirsch C, Oggier DM, Deprez P, Jakob C, Sommer T, and Aebi M. 2009. Htm1 protein

508 generates the $\mathrm{N}$-glycan signal for glycoprotein degradation in the endoplasmic

$509 \quad$ reticulum. J Cell Biol 184:159-172. 10.1083/jcb.200809198

510 Crowder JJ, Geigges M, Gibson RT, Fults ES, Buchanan BW, Sachs N, Schink A, Kreft SG, and

511 Rubenstein EM. 2015. Rkr1/Ltn1 Ubiquitin Ligase-Mediated Degradation of

512 Translationally Stalled Endoplasmic Reticulum Proteins. J Biol Chem 290:18454-

$513 \quad$ 18466. $10.1074 /$ jbc.M115.663559

514 Finley D, Ulrich HD, Sommer T, and Kaiser P. 2012. The ubiquitin-proteasome system of

$515 \quad$ Saccharomyces cerevisiae. Genetics 192:319-360.10.1534/genetics.112.140467

516 Fisher EA, Khanna NA, and McLeod RS. 2011. Ubiquitination regulates the assembly of

517 VLDL in HepG2 cells and is the committing step of the apoB-100 ERAD pathway.J

$518 \quad$ Lipid Res 52:1170-1180.10.1194/jlr.M011726

519 Gauss R, Sommer T, and Jarosch E. 2006. The Hrd1p ligase complex forms a linchpin

520 between ER-lumenal substrate selection and Cdc48p recruitment. Embo J 25:1827-

$521 \quad 1835.10 .1038 /$ sj.emboj.7601088

522 Goder V, and Melero A. 2011. Protein O-mannosyltransferases participate in ER protein

523 quality control. J Cell Sci 124:144-153. 10.1242/jcs.072181

524 Gronroos E, Hellman U, Heldin CH, and Ericsson J. 2002. Control of Smad7 stability by

525 competition between acetylation and ubiquitination. Mol Cell 10:483-493.

526 Guthrie C, and Fink GR. 2004. Guide to Yeast Genetics and Molecular and Cell Biology. San

527 Diego: Elsevier. 
528 Habeck G, Ebner FA, Shimada-Kreft H, and Kreft SG. 2015. The yeast ERAD-C ubiquitin

529 ligase Doa10 recognizes an intramembrane degron. J Cell Biol 209:261-273.

$530 \quad 10.1083 / j c b .201408088$

531 Hickey CM. 2016. Degradation elements coincide with cofactor binding sites in a short-lived 532 transcription factor. Cell Logist 6:e1157664. 10.1080/21592799.2016.1157664

533 Hiller MM, Finger A, Schweiger M, and Wolf DH. 1996. ER degradation of a misfolded $534 \quad$ luminal protein by the cytosolic ubiquitin-proteasome pathway. Science 273:1725$535 \quad 1728$.

536 Hirayama H, Fujita M, Yoko-o T, and Jigami Y. 2008. O-mannosylation is required for 537 degradation of the endoplasmic reticulum-associated degradation substrate Gas $1^{*} \mathrm{p}$ via the ubiquitin/proteasome pathway in Saccharomyces cerevisiae. J Biochem 143:555-567. 10.1093/jb/mvm249

Hjelm H, Sjodahl J, and Sjoquist J. 1975. Immunologically active and structurally similar 541 fragments of protein A from Staphylococcus aureus. Eur J Biochem 57:395-403.

542 Hollebeke J, Van Damme P, and Gevaert K. 2012. N-terminal acetylation and other functions 543 of Nalpha-acetyltransferases. Biol Chem 393:291-298. 10.1515/hsz-2011-0228

544 Hrizo SL, Gusarova V, Habiel DM, Goeckeler JL, Fisher EA, and Brodsky JL. 2007. The 545 Hsp110 molecular chaperone stabilizes apolipoprotein B from endoplasmic reticulum-associated degradation (ERAD). J Biol Chem 282:32665-32675. kush10.1074/jbc.M705216200

Hughes Hallett JE, Luo X, and Capaldi AP. 2015. Snf1/AMPK promotes the formation of Kog1/Raptor-bodies to increase the activation threshold of TORC1 in budding yeast. Elife 4. 10.7554/eLife.09181 
551 Huyer G, Piluek WF, Fansler Z, Kreft SG, Hochstrasser M, Brodsky JL, and Michaelis S. 2004.

552 Distinct machinery is required in Saccharomyces cerevisiae for the endoplasmic

553 reticulum-associated degradation of a multispanning membrane protein and a

$554 \quad$ soluble luminal protein. J Biol Chem 279:38369-38378.

555 Hwang CS, Shemorry A, and Varshavsky A. 2010. N-terminal acetylation of cellular proteins

556

557 creates specific degradation signals. Science 327:973-977.

558 Jiang W, Wang S, Xiao M, Lin Y, Zhou L, Lei Q, Xiong Y, Guan KL, and Zhao S. 2011.

559

560

561 10.1126/science.1183147

562

563

564

565

566

567

568

569

570

571

572

573

Acetylation regulates gluconeogenesis by promoting PEPCK1 degradation via recruiting the UBR5 ubiquitin ligase. Mol Cell 43:33-44.

$$
\text { 10.1016/j.molcel.2011.04.028 }
$$

Johnson PR, Swanson R, Rakhilina L, and Hochstrasser M. 1998. Degradation signal masking by heterodimerization of MATalpha2 and MATa1 blocks their mutual destruction by the ubiquitin-proteasome pathway. Cell 94:217-227.

Johnston M, and Davis RW. 1984. Sequences that regulate the divergent GAL1-GAL10 promoter in Saccharomyces cerevisiae. Mol Cell Biol 4:1440-1448.

Kleiger G, and Mayor T. 2014. Perilous journey: a tour of the ubiquitin-proteasome system. Trends Cell Biol 24:352-359. 10.1016/j.tcb.2013.12.003

Kushnirov VV. 2000. Rapid and reliable protein extraction from yeast. Yeast 16:857-860. 10.1002/1097-0061(20000630)16:9<857::AID-YEA561>3.0.CO;2-B

Lee KE, Heo JE, Kim JM, and Hwang CS. 2016. N-Terminal Acetylation-Targeted N-End Rule Proteolytic System: The Ac/N-End Rule Pathway. Mol Cells 39:169-178. 10.14348/molcells.2016.2329 
574 Liang JS, Kim T, Fang S, Yamaguchi J, Weissman AM, Fisher EA, and Ginsberg HN. 2003.

575 Overexpression of the tumor autocrine motility factor receptor Gp78, a ubiquitin

576 protein ligase, results in increased ubiquitinylation and decreased secretion of

577 apolipoprotein B100 in HepG2 cells. J Biol Chem 278:23984-23988.

$578 \quad 10.1074 /$ jbc.M302683200

579 Licklider LJ, Thoreen CC, Peng J, and Gygi SP. 2002. Automation of nanoscale microcapillary

$580 \quad$ liquid chromatography-tandem mass spectrometry with a vented column. Anal

$581 \quad$ Chem 74:3076-3083.

582 Metzger MB, Maurer MJ, Dancy BM, and Michaelis S. 2008. Degradation of a cytosolic 583

584 protein requires endoplasmic reticulum-associated degradation machinery. J Biol

585

586 Chem 283:32302-32316.

Nakayama KI, and Nakayama K. 2006. Ubiquitin ligases: cell-cycle control and cancer. Nat

587

588

589

590

591

592

593

594

595

596

$$
\text { Rev Cancer 6:369-381. 10.1038/nrc1881 }
$$

Nguyen TV, Lee JE, Sweredoski MJ, Yang SJ, Jeon SJ, Harrison JS, Yim JH, Lee SG, Handa H, Kuhlman B, Jeong JS, Reitsma JM, Park CS, Hess S, and Deshaies RJ. 2016. Glutamine Triggers Acetylation-Dependent Degradation of Glutamine Synthetase via the Thalidomide Receptor Cereblon. Mol Cell 61:809-820. 10.1016/j.molcel.2016.02.032

Pariyarath R, Wang H, Aitchison JD, Ginsberg HN, Welch WJ, Johnson AE, and Fisher EA. 2001. Co-translational interactions of apoprotein B with the ribosome and translocon during lipoprotein assembly or targeting to the proteasome. J Biol Chem 276:541-550. 10.1074/jbc.M007944200

Pehar M, Lehnus M, Karst A, and Puglielli L. 2012. Proteomic assessment shows that many endoplasmic reticulum (ER)-resident proteins are targeted by N(epsilon)-lysine 
acetylation in the lumen of the organelle and predicts broad biological impact. J Biol Chem 287:22436-22440. 10.1074/jbc.C112.362871

599 Pehar M, and Puglielli L. 2013. Lysine acetylation in the lumen of the ER: a novel and 600 601 essential function under the control of the UPR. Biochim Biophys Acta 1833:686-697.

Ravid T, Kreft SG, and Hochstrasser M. 2006. Membrane and soluble substrates of the 10.1016/j.bbamcr.2012.12.004

Polevoda B, Arnesen T, and Sherman F. 2009. A synopsis of eukaryotic Nalpha-terminal acetyltransferases: nomenclature, subunits and substrates. BMC Proc 3 Suppl 6:S2.

10.1186/1753-6561-3-S6-S2

Quan EM, Kamiya Y, Kamiya D, Denic V, Weibezahn J, Kato K, and Weissman JS. 2008. Defining the glycan destruction signal for endoplasmic reticulum-associated degradation. Mol Cell 32:870-877. 10.1016/j.molcel.2008.11.017

Ravid T, and Hochstrasser M. 2008. Diversity of degradation signals in the ubiquitinproteasome system. Nat Rev Mol Cell Biol 9:679-690.

612 Rubenstein EM, and Hochstrasser M. 2010. Redundancy and variation in the ubiquitinmediated proteolytic targeting of a transcription factor. Cell Cycle 9:4282-4285. 13741 [pii] Doa10 ubiquitin ligase are degraded by distinct pathways. Embo J 25:533-543.

Rubenstein EM, Kreft SG, Greenblatt W, Swanson R, and Hochstrasser M. 2012. Aberrant substrate engagement of the ER translocon triggers degradation by the Hrd1 ubiquitin ligase. J Cell Biol 197:761-773. 10.1083/jcb.201203061

Ruggiano A, Foresti O, and Carvalho P. 2014. Quality control: ER-associated degradation: protein quality control and beyond. J Cell Biol 204:869-879. 10.1083/jcb.201312042 
620 Rutledge AC, Qiu W, Zhang R, Kohen-Avramoglu R, Nemat-Gorgani N, and Adeli K. 2009.

621

622

623

624

625

626

627

628

629

630

631

632

633

634

635

636

637

638

639

640

641

Mechanisms targeting apolipoprotein B100 to proteasomal degradation: evidence that degradation is initiated by BiP binding at the $\mathrm{N}$ terminus and the formation of a p97 complex at the C terminus. Arterioscler Thromb Vasc Biol 29:579-585.

10.1161/ATVBAHA.108.181859

Sato BK, Schulz D, Do PH, and Hampton RY. 2009. Misfolded membrane proteins are specifically recognized by the transmembrane domain of the Hrd1p ubiquitin ligase. Mol Cell 34:212-222. 10.1016/j.molcel.2009.03.010

Scott DC, and Schekman R. 2008. Role of Sec61p in the ER-associated degradation of shortlived transmembrane proteins. J Cell Biol 181:1095-1105. 10.1083/jcb.200804053

Spear ED, and Ng DT. 2005. Single, context-specific glycans can target misfolded glycoproteins for ER-associated degradation. J Cell Biol 169:73-82. vas10.1083/jcb.200411136

Stolz A, Besser S, Hottmann H, and Wolf DH. 2013. Previously unknown role for the ubiquitin ligase Ubr1 in endoplasmic reticulum-associated protein degradation. Proc Natl Acad Sci U S A 110:15271-15276. 10.1073/pnas.1304928110

Vashist S, Kim W, Belden WJ, Spear ED, Barlowe C, and Ng DT. 2001. Distinct retrieval and retention mechanisms are required for the quality control of endoplasmic reticulum protein folding. J Cell Biol 155:355-368. 10.1083/jcb.200106123

von der Malsburg K, Shao S, and Hegde RS. 2015. The Ribosome Quality Control Pathway can Access Nascent Polypeptides Stalled at the Sec61 Translocon. Mol Biol Cell. 10.1091/mbc.E15-01-0040 
642 Watts SG, Crowder JJ, Coffey SZ, and Rubenstein EM. 2015. Growth-based Determination 643 and Biochemical Confirmation of Genetic Requirements for Protein Degradation in $644 \quad$ Saccharomyces cerevisiae. J Vis Exp:e52428. 10.3791/52428

645 Weisgraber KH, Innerarity TL, and Mahley RW. 1978. Role of lysine residues of plasma 646 lipoproteins in high affinity binding to cell surface receptors on human fibroblasts. J $647 \quad$ Biol Chem 253:9053-9062.

648 Xu C, Wang S, Thibault G, and Ng DT. 2013. Futile protein folding cycles in the ER are 649 terminated by the unfolded protein 0-mannosylation pathway. Science 340:978-

650 981. $10.1126 /$ science.1234055

651 Yeung SJ, Chen SH, and Chan L. 1996. Ubiquitin-proteasome pathway mediates intracellular 652 degradation of apolipoprotein B. Biochemistry 35:13843-13848. $10.1021 /$ bi9618777

654 Zattas D, Adle DJ, Rubenstein EM, and Hochstrasser M. 2013. N-terminal acetylation of the 655 yeast Derlin Der1 is essential for Hrd1 ubiquitin-ligase activity toward luminal ER substrates. Mol Biol Cell 24:890-900. 10.1091/mbc.E12-11-0838

Zattas D, and Hochstrasser M. 2015. Ubiquitin-dependent protein degradation at the yeast endoplasmic reticulum and nuclear envelope. Crit Rev Biochem Mol Biol 50:1-17.

661 Huyer G, Piluek WF, Fansler Z, Kreft SG, Hochstrasser M, Brodsky JL, and Michaelis S. 2004. 662 Distinct machinery is required in Saccharomyces cerevisiae for the endoplasmic 663 reticulum-associated degradation of a multispanning membrane protein and a soluble luminal protein. J Biol Chem 279:38369-38378. 
665 Hwang CS, Shemorry A, and Varshavsky A. 2010. N-terminal acetylation of cellular proteins 666 creates specific degradation signals. Science 327:973-977. 10.1126/science.1183147

667 Johnson PR, Swanson R, Rakhilina L, and Hochstrasser M. 1998. Degradation signal masking by 668 heterodimerization of MATalpha2 and MATa1 blocks their mutual destruction by the 669 ubiquitin-proteasome pathway. Cell 94:217-227.

670 Johnston M, and Davis RW. 1984. Sequences that regulate the divergent GAL1-GAL10 671 promoter in Saccharomyces cerevisiae. Mol Cell Biol 4:1440-1448.

672 Kleiger G, and Mayor T. 2014. Perilous journey: a tour of the ubiquitin-proteasome system. 673 Trends Cell Biol 24:352-359. 10.1016/j.tcb.2013.12.003

674 Kushnirov VV. 2000. Rapid and reliable protein extraction from yeast. Yeast 16:857-860. 675 10.1002/1097-0061(20000630)16:9<857::AID-YEA561>3.0.CO;2-B

676 Lee KE, Heo JE, Kim JM, and Hwang CS. 2016. N-Terminal Acetylation-Targeted N-End Rule 677 Proteolytic System: The Ac/N-End Rule Pathway. Mol Cells 39:169-178. 678 10.14348/molcells.2016.2329

679 Liang JS, Kim T, Fang S, Yamaguchi J, Weissman AM, Fisher EA, and Ginsberg HN. 2003. 680 Overexpression of the tumor autocrine motility factor receptor Gp78, a ubiquitin protein 681 682 ligase, results in increased ubiquitinylation and decreased secretion of apolipoprotein B100 in HepG2 cells. J Biol Chem 278:23984-23988. 10.1074/jbc.M302683200

683 Licklider LJ, Thoreen CC, Peng J, and Gygi SP. 2002. Automation of nanoscale microcapillary 684 liquid chromatography-tandem mass spectrometry with a vented column. Anal Chem 685 74:3076-3083. 
686 Metzger MB, Maurer MJ, Dancy BM, and Michaelis S. 2008. Degradation of a cytosolic protein 687 requires endoplasmic reticulum-associated degradation machinery. J Biol Chem $688 \quad 283: 32302-32316$.

689 Nakayama KI, and Nakayama K. 2006. Ubiquitin ligases: cell-cycle control and cancer. Nat Rev 690 Cancer 6:369-381. 10.1038/nrc1881

691 Ng DT, Spear ED, and Walter P. 2000. The unfolded protein response regulates multiple aspects 692 of secretory and membrane protein biogenesis and endoplasmic reticulum quality control.

693 J Cell Biol 150:77-88.

694 Nguyen TV, Lee JE, Sweredoski MJ, Yang SJ, Jeon SJ, Harrison JS, Yim JH, Lee SG, Handa H, 695

696 697

Pariyarath R, Wang H, Aitchison JD, Ginsberg HN, Welch WJ, Johnson AE, and Fisher EA. Kuhlman B, Jeong JS, Reitsma JM, Park CS, Hess S, and Deshaies RJ. 2016. Glutamine Triggers Acetylation-Dependent Degradation of Glutamine Synthetase via the Thalidomide Receptor Cereblon. Mol Cell 61:809-820. 10.1016/j.molcel.2016.02.032

700

701 2001. Co-translational interactions of apoprotein B with the ribosome and translocon during lipoprotein assembly or targeting to the proteasome. J Biol Chem 276:541-550. 10.1074/jbc.M007944200

Polevoda B, Arnesen T, and Sherman F. 2009. A synopsis of eukaryotic Nalpha-terminal acetyltransferases: nomenclature, subunits and substrates. BMC Proc 3 Suppl 6:S2. $10.1186 / 1753-6561-3-S 6-S 2$

Quan EM, Kamiya Y, Kamiya D, Denic V, Weibezahn J, Kato K, and Weissman JS. 2008. 706 Defining the glycan destruction signal for endoplasmic reticulum-associated degradation. Mol Cell 32:870-877. 10.1016/j.molcel.2008.11.017 
708 Ravid T, and Hochstrasser M. 2008. Diversity of degradation signals in the ubiquitin-proteasome 709 system. Nat Rev Mol Cell Biol 9:679-690.

710 Ravid T, Kreft SG, and Hochstrasser M. 2006. Membrane and soluble substrates of the Doa10 711 ubiquitin ligase are degraded by distinct pathways. Embo J 25:533-543.

712 Rubenstein EM, and Hochstrasser M. 2010. Redundancy and variation in the ubiquitin-mediated proteolytic targeting of a transcription factor. Cell Cycle 9:4282-4285. 13741 [pii]

714 Rubenstein EM, Kreft SG, Greenblatt W, Swanson R, and Hochstrasser M. 2012. Aberrant substrate engagement of the ER translocon triggers degradation by the Hrd1 ubiquitin ligase. J Cell Biol 197:761-773. 10.1083/jcb.201203061

717 Ruggiano A, Foresti O, and Carvalho P. 2014. Quality control: ER-associated degradation: protein quality control and beyond. J Cell Biol 204:869-879. 10.1083/jcb.201312042

719 Rutledge AC, Qiu W, Zhang R, Kohen-Avramoglu R, Nemat-Gorgani N, and Adeli K. 2009. Mechanisms targeting apolipoprotein B100 to proteasomal degradation: evidence that degradation is initiated by $\mathrm{BiP}$ binding at the $\mathrm{N}$ terminus and the formation of a $\mathrm{p} 97$ complex at the C terminus. Arterioscler Thromb Vasc Biol 29:579-585.

727 Scott DC, and Schekman R. 2008. Role of Sec61p in the ER-associated degradation of short728 lived transmembrane proteins. J Cell Biol 181:1095-1105. 10.1083/jcb.200804053

729 Sikorski RS, and Hieter P. 1989. A system of shuttle vectors and yeast host strains designed for 730 efficient manipulation of DNA in Saccharomyces cerevisiae. Genetics 122:19-27. 
731 Spear ED, and Ng DT. 2005. Single, context-specific glycans can target misfolded glycoproteins

732 for ER-associated degradation. J Cell Biol 169:73-82. vas10.1083/jcb.200411136

733 Stolz A, Besser S, Hottmann H, and Wolf DH. 2013. Previously unknown role for the ubiquitin 734 ligase Ubr1 in endoplasmic reticulum-associated protein degradation. Proc Natl Acad Sci 735 US A 110:15271-15276. 10.1073/pnas.1304928110

736 Tong AH, Evangelista M, Parsons AB, Xu H, Bader GD, Page N, Robinson M, Raghibizadeh S, 737 Hogue CW, Bussey H, Andrews B, Tyers M, and Boone C. 2001. Systematic genetic

738

739 analysis with ordered arrays of yeast deletion mutants. Science 294:2364-2368.

740

Vashist S, Kim W, Belden WJ, Spear ED, Barlowe C, and Ng DT. 2001. Distinct retrieval and

741

742

743

744

745

746

747

748

749

750

751 retention mechanisms are required for the quality control of endoplasmic reticulum protein folding. J Cell Biol 155:355-368. 10.1083/jcb.200106123

von der Malsburg K, Shao S, and Hegde RS. 2015. The Ribosome Quality Control Pathway can Access Nascent Polypeptides Stalled at the Sec61 Translocon. Mol Biol Cell. 10.1091/mbc.E15-01-0040

Watts SG, Crowder JJ, Coffey SZ, and Rubenstein EM. 2015. Growth-based Determination and Biochemical Confirmation of Genetic Requirements for Protein Degradation in Saccharomyces cerevisiae. J Vis Exp:e52428. 10.3791/52428

Weisgraber KH, Innerarity TL, and Mahley RW. 1978. Role of lysine residues of plasma lipoproteins in high affinity binding to cell surface receptors on human fibroblasts. $J$ Biol Chem 253:9053-9062. 
$752 \mathrm{Xu} \mathrm{C}$, Wang S, Thibault G, and Ng DT. 2013. Futile protein folding cycles in the ER are

753 terminated by the unfolded protein O-mannosylation pathway. Science 340:978-981.

$754 \quad 10.1126 /$ science. 1234055

755 Yeung SJ, Chen SH, and Chan L. 1996. Ubiquitin-proteasome pathway mediates intracellular 756 degradation of apolipoprotein B. Biochemistry 35:13843-13848. 10.1021/bi9618777

757 Zattas D, Adle DJ, Rubenstein EM, and Hochstrasser M. 2013. N-terminal acetylation of the 758 yeast Derlin Der1 is essential for Hrd1 ubiquitin-ligase activity toward luminal ER $759 \quad$ substrates. Mol Biol Cell 24:890-900. 10.1091/mbc.E12-11-0838

760 Zattas D, and Hochstrasser M. 2015. Ubiquitin-dependent protein degradation at the yeast 761 endoplasmic reticulum and nuclear envelope. Crit Rev Biochem Mol Biol 50:1-17. $762 \quad 10.3109 / 10409238.2014 .959889$

763

764 


\section{Figure 1}

\section{Acetylation of Deg1-Sec62-N153D.}

(A) Schematic of Deg1-Sec62 following aberrant translocon engagement. Deg1-Sec62 possesses, in sequence, Deg1 (the N-terminal 67 amino acids from the yeast transcriptional repressor MAT $\alpha 2$ ), a Flag epitope (F), the two-transmembrane protein Sec62, and tandem copies of Protein A (PrA) from Staphylococcus aureus. Following co-translational insertion of the two transmembrane segments of Sec62 (black ovals), a portion of the cytosolic $\mathrm{N}$ terminal tail aberrantly moves into the translocon via the post-translational translocation mechanism. Aberrant translocation is followed by N-linked glycosylation of Asn153 and Hrd1dependent ubiquitylation (Rubenstein et al. 2012). (B) Purification of Deg1-Sec62-N153D. Deg1-Sec62-N153D was immunoprecipitated from lysates of hrd1 $\Delta$ cells, separated by SDSPAGE, and stained with GelCode Blue. Bands corresponding to Deg1-Sec62-N153D (demarcated by box) were excised, subjected to in-gel digestion, and evaluated by LC/ESI MS/MS. (C) Peptide map of Deg1-Sec62-N153D. High confidence peptide identifications from SEQUEST-HT (false discovery rate $<1 \%$ ) were mapped to the Deg1-Sec62-N153D protein sequence. Regions highlighted in green are segments of the amino acid sequence identified by MS. Amino acids identified as acetylated are labeled "A". Underlined amino acids represent detection of methionine oxidation, a likely artifact of electrospray MS (Chen $\&$ Cook 2007). Italicized amino acids represent cysteine residues modified by carbamidomethylation following iodoacetamide treatment. (D - F) Tandem mass spectra of proteolytically digested Deg1-Sec62-N153D were subjected to acetylpeptide identification using the database search algorithm SEQUEST-HT (part of Proteome Discoverer). The tables display predicted fragment ions for the identified peptides and highlight in red and blue the b- and y-ions, respectively, identified in the fragment spectra. Red and blue peaks in the fragment spectra reflect tandem MS data that matched theoretical peptide fragment masses listed in the tables. 
ammonia. N, Amino terminus. C, Carboxyl terminus. Ub, ubiquitin. Ac, acetylation. Ox, oxidation.

A

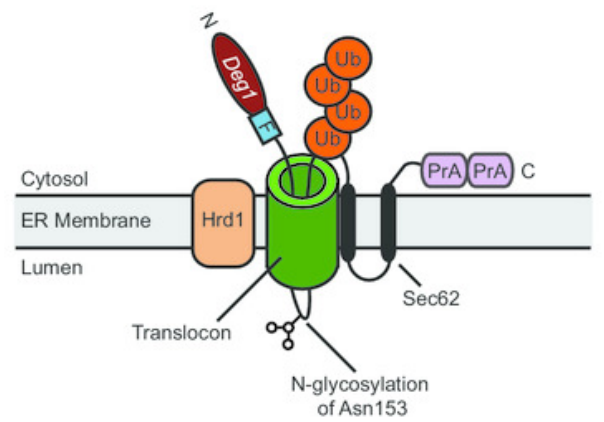

D

Mono isotopic $\mathrm{m} / \mathrm{z}: 557.31995 \mathrm{Da}(-0.55 \mathrm{mmu} /-0.98 \mathrm{ppm})$

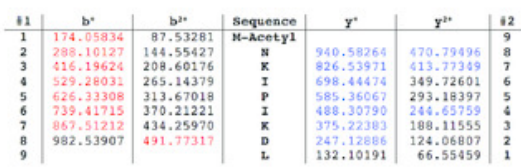

B

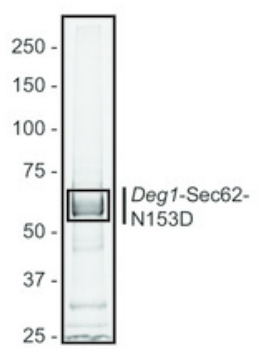

C

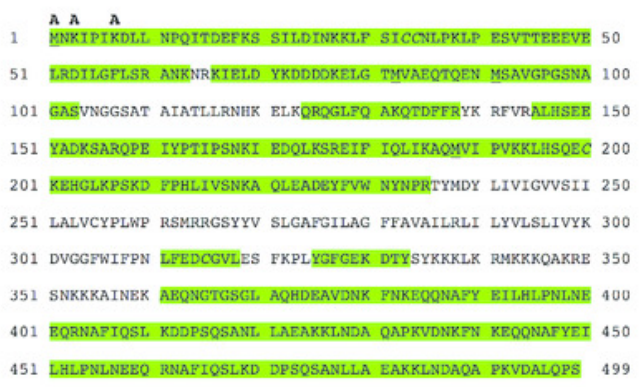

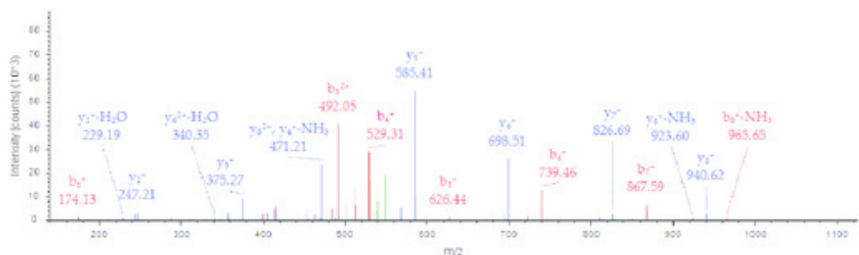

$E$

M-OXN K-AC I P I KD L L NP Q IT DE F K

Monoisotopic m/z: $772.41351 \mathrm{Da}(-1.89 \mathrm{mmu} /-2.45 \mathrm{ppm})$
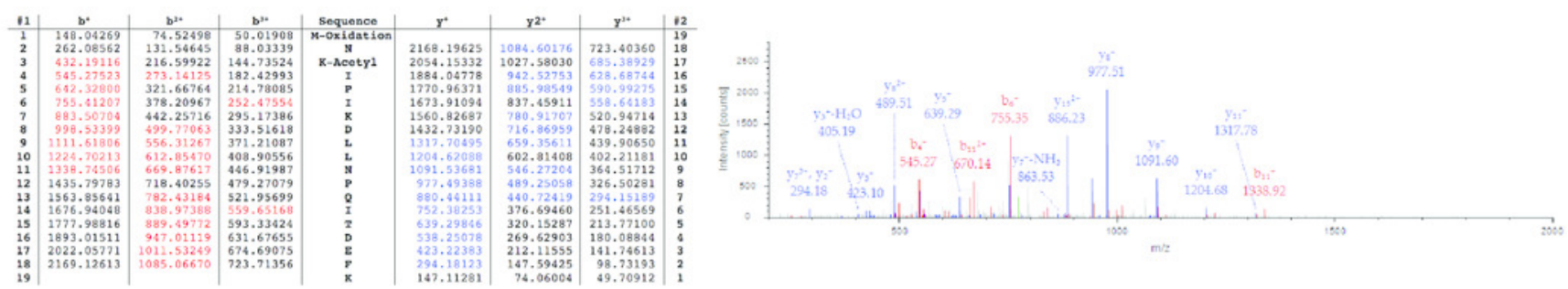

F

MNKIPIK-ACDLLNPQITDEFK

Monoisotopic m/z: 767.08356 Da (-0.21 mmu/ -0.27 ppm)
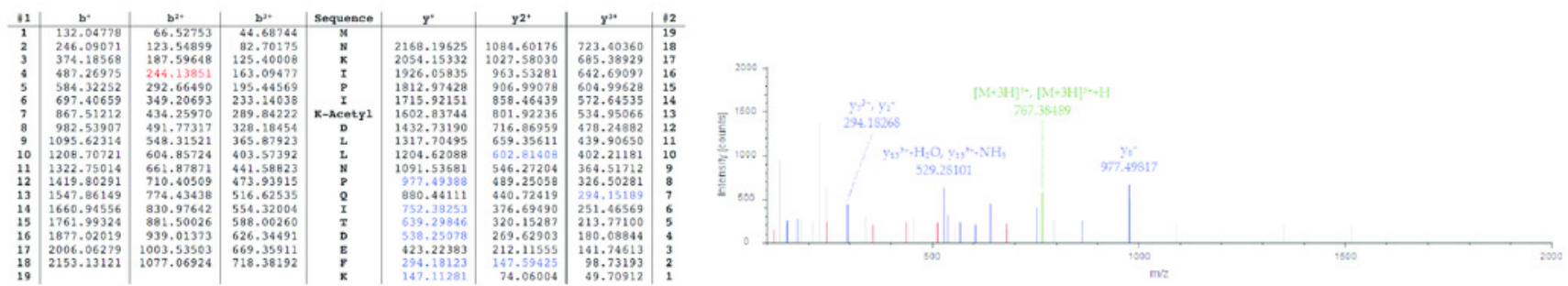


\section{Figure 2}

Neither N-terminal acetylation nor internal acetylation is required for Hrd1-dependent degradation of Deg1*-Sec62.

(A) Cycloheximide chase analysis of yeast cells of the indicated genotypes expressing Deg1*-Sec62 or harboring an empty vector. (B) Cycloheximide chase analysis of yeast cells of the indicated genotypes expressing HA-tagged CPY*. (C) Cycloheximide chase analysis of wild-type yeast cells expressing variants of Deg1*-Sec62 or harboring an empty vector. (D) Lysates from hrd1 1 cells expressing the indicated variants of Deg1*-Sec62 or harboring an empty vector were incubated in the absence or presence of Endo $\mathrm{H}$. The black line indicates that intervening lanes have been omitted. (E) Cycloheximide chase analysis of yeast cells of the indicated genotypes expressing Deg1*-Sec62-2R or harboring an empty vector. (F) Cycloheximide chase analysis of yeast cells of the indicated genotypes expressing Deg1*Sec62-3R or harboring an empty vector. Pgk1 serves as a loading control for panels A, B, C, $E$, and $F$. For each cycloheximide chase, the percentage of protein remaining at each time point (normalized to Pgk1) is indicated below the image. Experiments depicted in panels A, C, $\mathrm{E}$, and $\mathrm{F}$ were repeated at least three times, and a representative image is presented for each. The control experiment in panel B (to verify previously published behavior of the tested strains with respect to CPY* degradation (Hiller et al. 1996; Zattas et al. 2013) and assessment of Endo $\mathrm{H}$ sensitivity in panel $\mathrm{D}$ (to confirm protein $\mathrm{N}$-linked glycosylation status) were each performed one time. Vec, Vector. WT, wild-type. OR, no mutation of acetylation sites. 2R, Lys3 and Lys7 mutated to Arg to prevent internal acetylation. 3R, Asn2, Lys3, and Lys7 mutated to Arg to prevent $\mathrm{N}$-terminal and internal acetylation. 


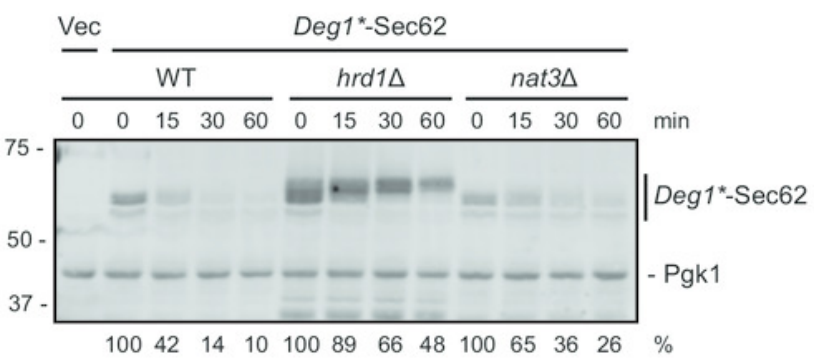

C

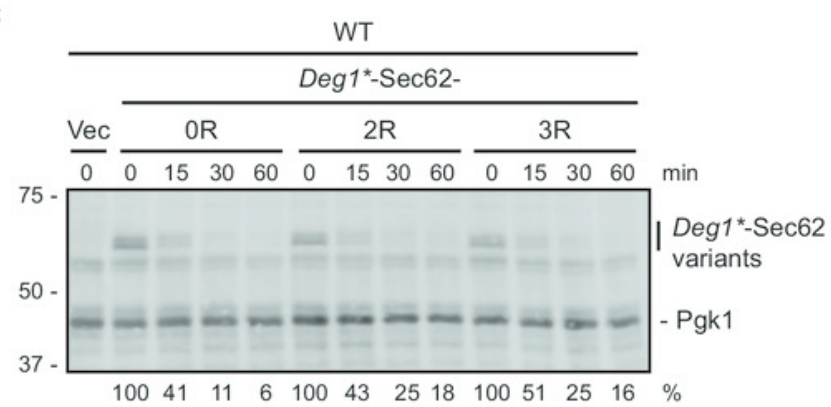

E

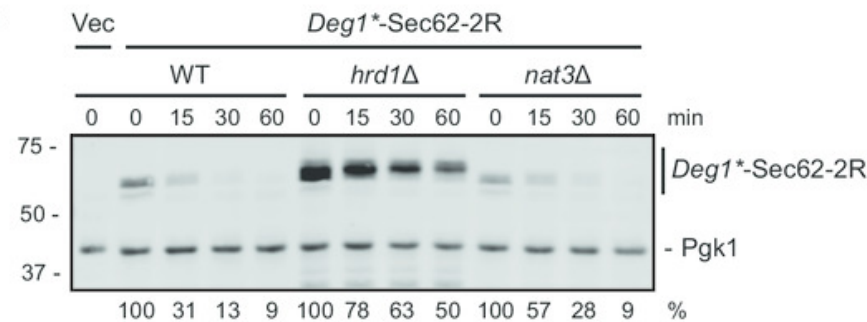

B

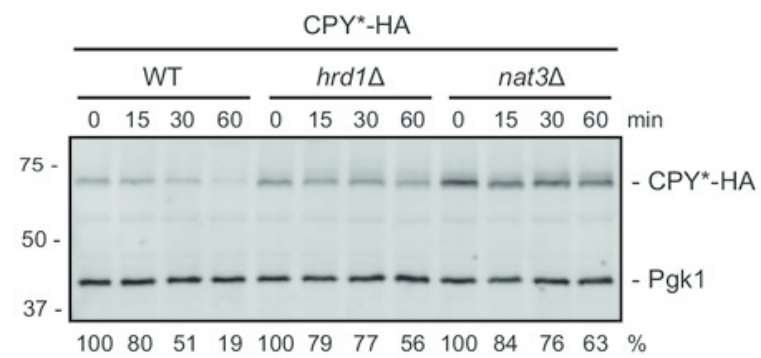

D

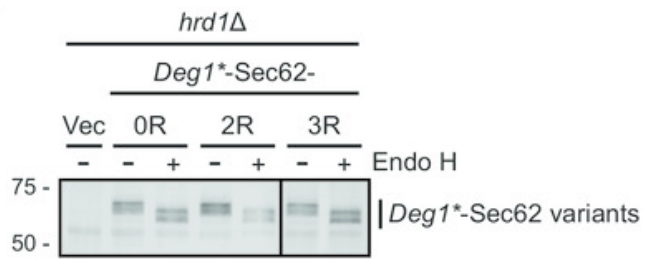

F

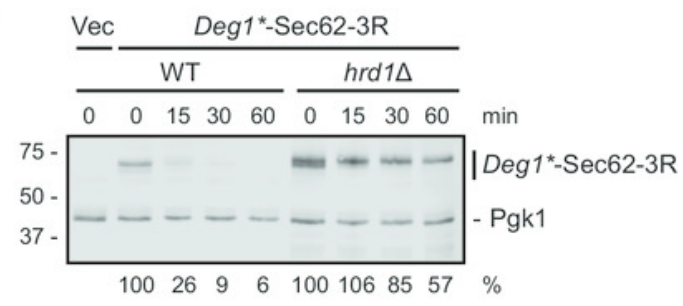




\section{Table $\mathbf{1}$ (on next page)}

Yeast strains used in this study. 
1 Table 1.

\begin{tabular}{|c|c|c|c|}
\hline Name & Alias & Genotype & Source \\
\hline VJY20 & MHY6601 & $\begin{array}{l}\text { MAT } \alpha \text { his3- } 4200 \text { leu2-3,112 ura3-52 } \\
\text { lys2-801 trp1-1 gal2 nat3 } \Delta:: \text { TRP1 }\end{array}$ & $\begin{array}{l}\text { Mark } \\
\text { Hochstrasser and } \\
\text { David Adle }\end{array}$ \\
\hline VJY22 & MHY3032 & 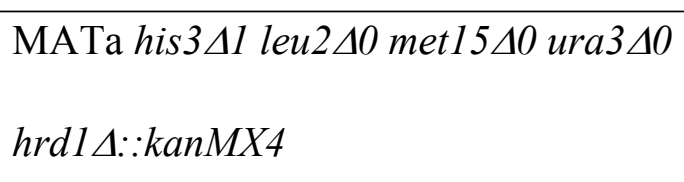 & (Tong et al. 2001) \\
\hline VJY42 & MHY501 & $\begin{array}{l}\text { MAT } \alpha \text { his3-4200 leu2-3,112 ura3-52 } \\
\text { lys2-801 trp1-1 gal2 }\end{array}$ & (Chen et al. 1993) \\
\hline VJY172 & MHY6199 & $\begin{array}{l}\text { MAT } \alpha \text { his3-4200 leu2-3,112 ura3-52 } \\
\text { lys2-801 trp1-1 gal2 hrd14::kanMX4 }\end{array}$ & $\begin{array}{l}\text { (Buchanan et al. } \\
\text { 2016) }\end{array}$ \\
\hline
\end{tabular}

2

3

4 
Table 2 (on next page)

Plasmids used in this study. 


\section{Table 2}

\begin{tabular}{|c|c|c|c|}
\hline Name & Alias & Description & Source \\
\hline pVJ2 & pDN431 & $\begin{array}{l}\text { CPY*-HA driven by } P R C 1 \text { promoter } \\
\mathrm{CPY}^{*}=\mathrm{CPY} \text { with } \mathrm{G} 255 \mathrm{R} \text { point mutation }\end{array}$ & $\begin{array}{l}\text { (Ng et al. } \\
2000)\end{array}$ \\
\hline pVJ27 & pRS316 & empty vector & $\begin{array}{l}\text { (Sikorski \& } \\
\text { Hieter 1989) }\end{array}$ \\
\hline pVJ312 & $\begin{array}{l}\text { pRS316- } \\
\text { GAL1/10-Deg1- } \\
\text { Sec62-ProtA-N153D }\end{array}$ & $\begin{array}{l}\text { Deg1-Sec62-ProtA-N153D driven by } \\
\text { GAL1/10 promoter }\end{array}$ & $\begin{array}{l}\text { (Scott \& } \\
\text { Schekman } \\
\text { 2008) }\end{array}$ \\
\hline pVJ317 & $\begin{array}{l}\text { pRS416-MET25- } \\
\text { Deg1*-Sec62-ProtA }\end{array}$ & $\begin{array}{l}\text { Degl*-Sec62-ProtA driven by } M E T 25 \\
\text { promoter } \\
\text { Degl* = Degl with F18S, I22T point } \\
\text { mutations }\end{array}$ & $\begin{array}{l}\text { (Rubenstein } \\
\text { et al. 2012) }\end{array}$ \\
\hline pVJ518 & $\begin{array}{l}\text { pRS416-MET25- } \\
\text { Deg1*-Sec62- } \\
\text { ProtA-2R }\end{array}$ & $\begin{array}{l}\text { Degl*-Sec62-ProtA-2R driven by MET25 } \\
\text { promoter } \\
\text { 2R = K3R, K7R point mutations } \\
\text { Generated via site-directed mutagenesis of } \\
\text { plasmid pVJ317 using primers VJR270 } \\
\text { (5' } \\
\text { GAATAGAATTCCCATTAGAGACCTT } \\
\text { TTAAATC 3') and VJR271 (5', } \\
\text { GGTCTCTAATGGGAATTCTATTCAT } \\
\text { GGATCC 3'), which mutate Lys3 and }\end{array}$ & This study \\
\hline
\end{tabular}




\begin{tabular}{|c|c|c|c|}
\hline & & $\begin{array}{l}\text { Lys } 7 \text { to Arg and introduce a silent EcoRI } \\
\text { restriction site. }\end{array}$ & \\
\hline pVJ527 & $\begin{array}{l}\text { pRS416-MET25- } \\
\text { Deg1*-Sec62- } \\
\text { ProtA-3R }\end{array}$ & $\begin{array}{l}\text { Deg }{ }^{*} \text {-Sec62-ProtA-3R driven by MET25 } \\
\text { promoter } \\
\text { 3R = N2R, K3R, K7R point mutations } \\
\text { Generated via site-directed mutagenesis of } \\
\text { plasmid pVJ518 using primers VJR280 } \\
\text { (5' } \\
\text { CATGAGAAGAATACCCATTAGAGA } \\
\text { CCTTTTAAATC 3') and VJR281 (5' } \\
\text { CTAATGGGTATTCTTCTCATGGATC } \\
\text { CACTAG 3'), which mutate Asn2 to Arg } \\
\text { and silently remove an EcoRI restriction } \\
\text { site. }\end{array}$ & This study \\
\hline
\end{tabular}

2 Note: All plasmids used in this study are yeast $C E N$ plasmids, harbor the $A m p R$ gene for

3 selection of ampicillin-resistant E. coli, and the $U R A 3$ gene for selection for uracil prototrophy in 4 yeast.

5

6 